Fig.1-10 Heygate Estate (series) [Photo: Author, 2012-2013
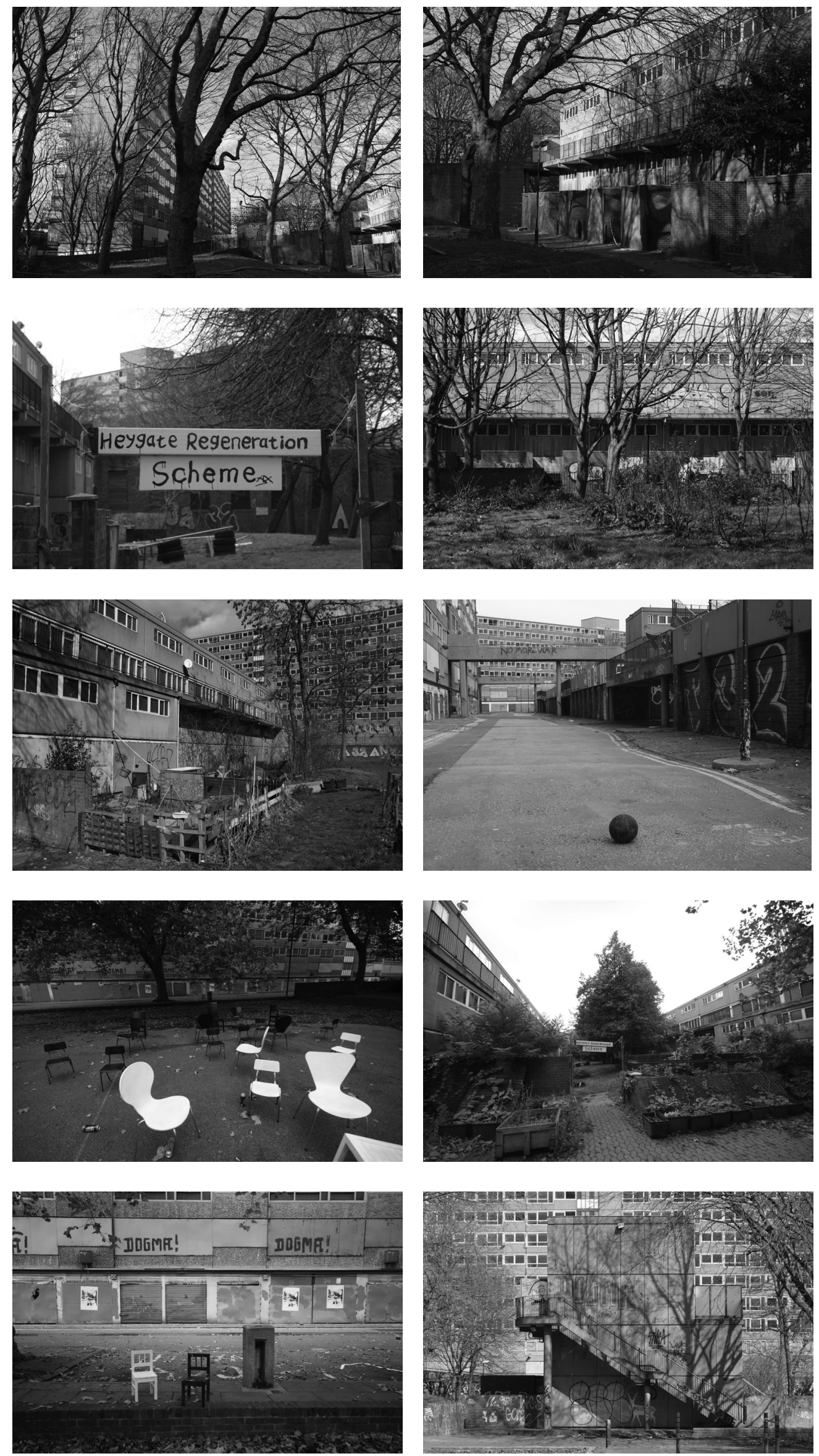


\title{
Immaterial densities: Revealing an alternative Heygate Estate
}

\author{
Felipe Lanuza Rilling
}

Built between 1970 and 1974 after the demolition of a dense fabric of old Victorian tenement buildings, the Heygate Estate in the London Borough of Southwark is the product of the late phase of urban and architectural modernism associated with the British Welfare State. After an initial phase of prosperity, the estate began to deteriorate and developed a negative reputation. Today, after a controversial eviction process lead by the local council, a set of 23 buildings containing 1260 housing units are almost completely vacated and awaiting demolition in order to give way to an ambitious regeneration project. The forced displacement, gentrification and privatisation of public land and the felling of almost all trees, which were planted as part of the modernist project and constituted a dense urban forest, were strongly contested by local campaigners and communities.

Suspended between past and future, the Heygate Estate now appears as a vacuum detached from regular urban activity. This interim condition opens up opportunities for alternative interpretations and modes of occupancy, holding histories not inscribed in the formal structures of the present city and offering possibilities outside the framework of an imposing modern urbanisation (cf. Aureli 2010). It suggests a future that is still open, while processes of decay and the invasion of nature progressively erode a place that has been severed from the urban matrix. These kinds of places constitute absences in the city, first documented by David Plowden and other urban photographers of the 1960s, who turned their gaze to the abandoned urban sites which started to flourish in the post-industrial cities of Europe and the USA, as Ignasi de Solá-Morales observed (1995). For them, photography offered an important means of exploration of their potential value, beyond the formal documentation or portrayal of cities.

The superimposed photographs of the Heygate Estate depicted in this issue of Interstices are intended to recreate the sense of richness and openness that now emanates from the site. The transparency of the images intimates both their mode of production and reading, suggesting an immaterial density and depth. Multiplicity and simultaneity are generated by allowing the intersection of different times and perspectives in a single image: interrogating the materiality of the Heygate Estate and its persistence in time, months before its anticipated demolition.

Photography etymologically means "writing of light", and a photograph itself is in a way a projection of the light of a past moment, hence the proposed images can be seen as palimpsests of light that reimagine the site both as memory and projection. The metaphor of the palimpsest is used in urban history to describe the way in which territories accumulate traces and elements of past uses and physical configurations: different stages of history "inscribed" in the present materiality of the city. Here, however, the idea of the palimpsest is shifted to a field more related to perception, composing an atmosphere that reveals traces and fragments of current and past states of the site, representing the richness of an absence about to disappear. 


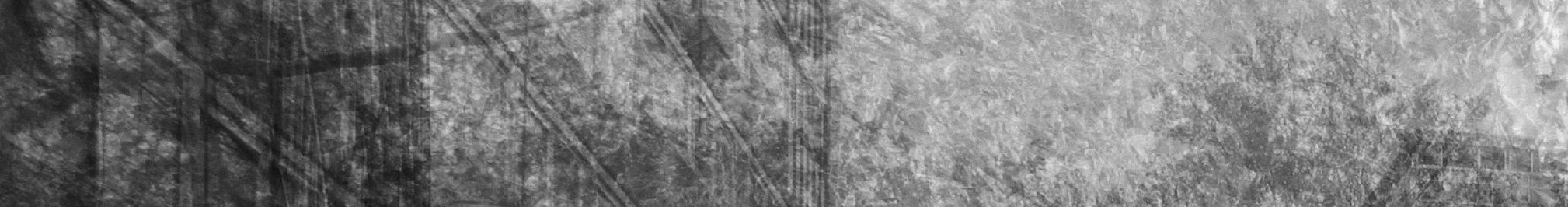

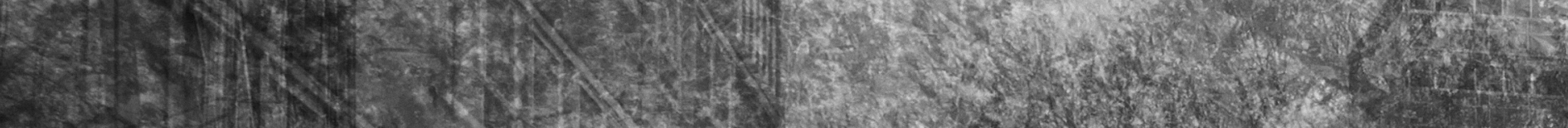

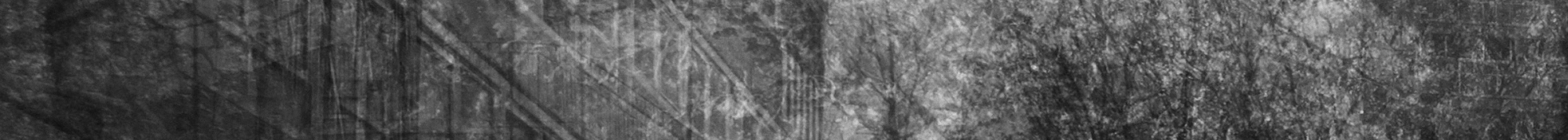
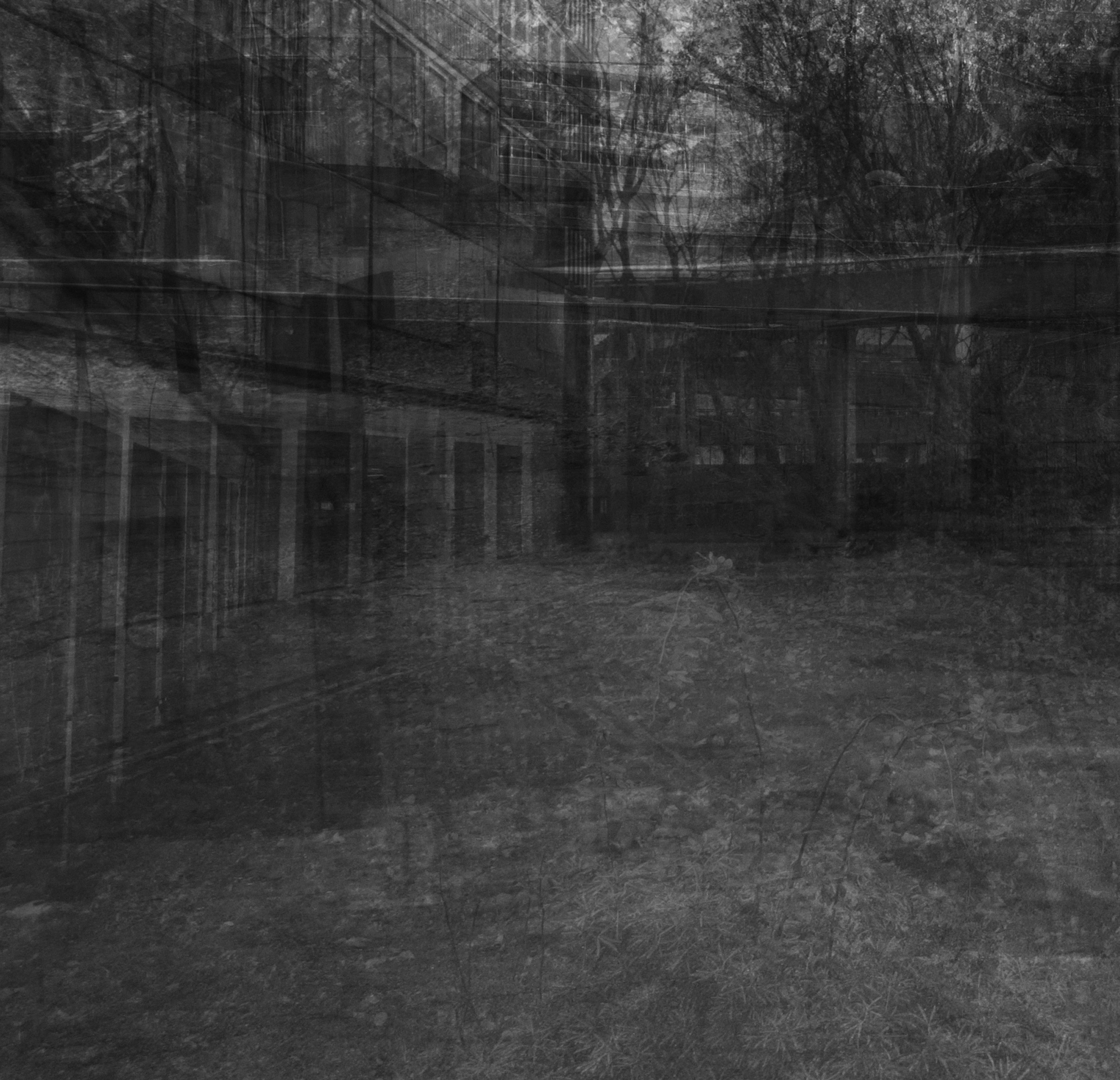

9
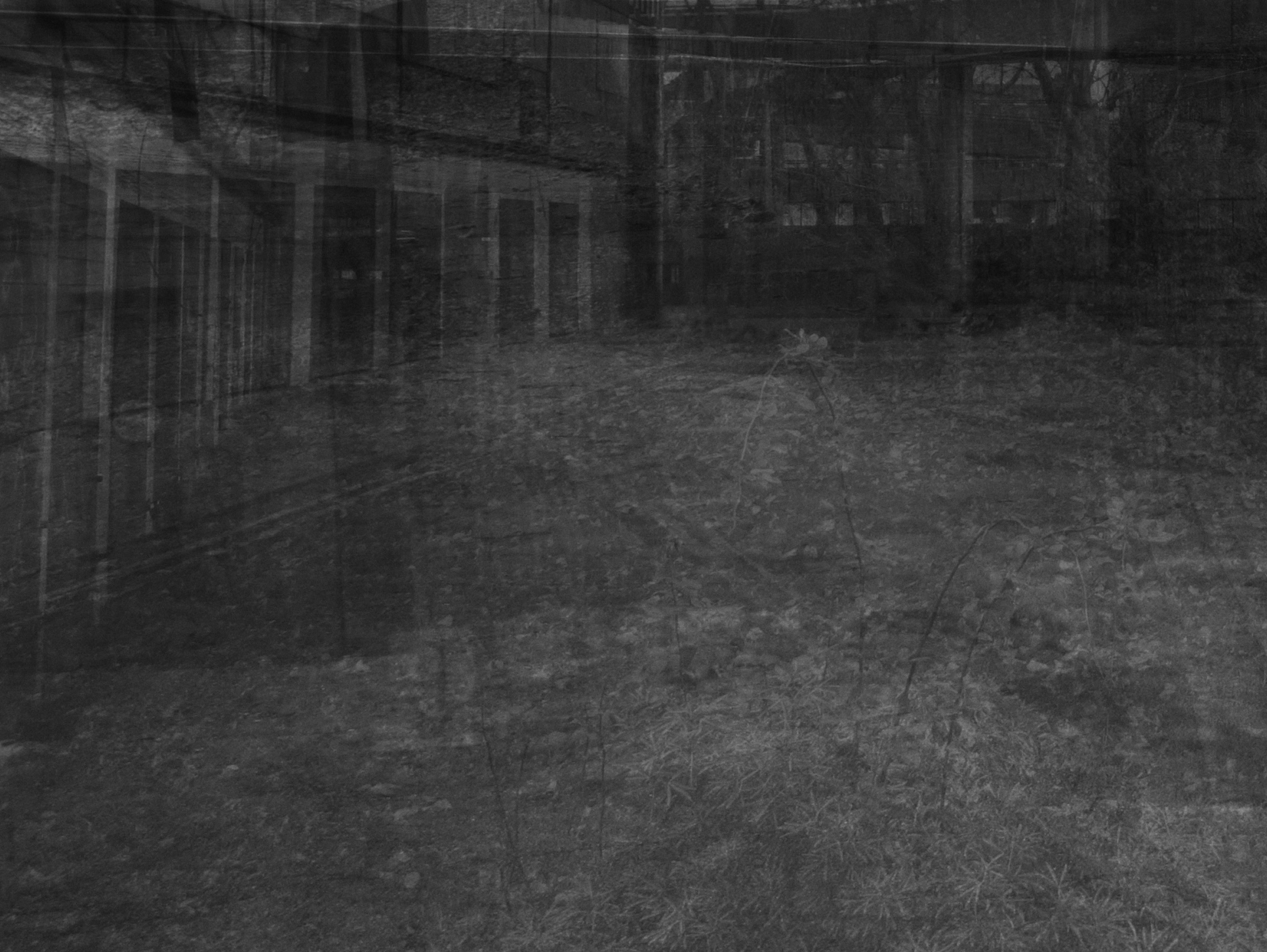

$$
\text { if } 1 \text { if }
$$




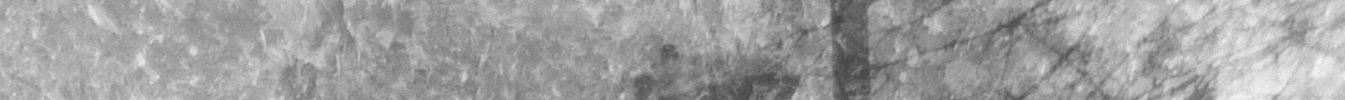

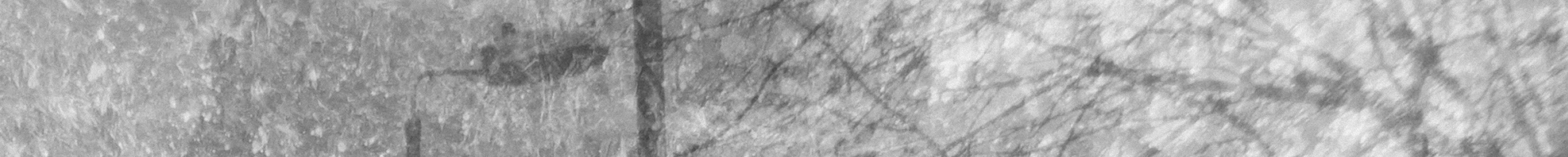

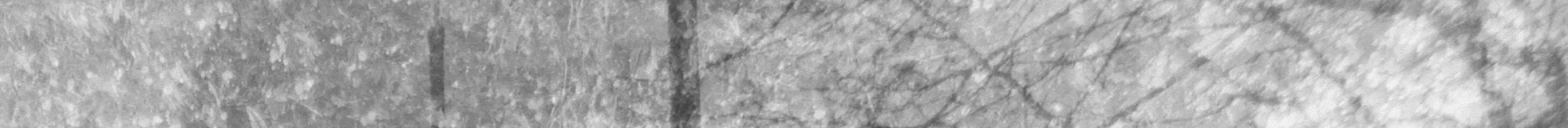

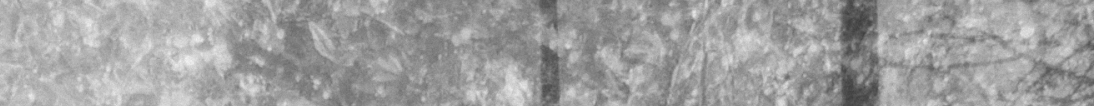

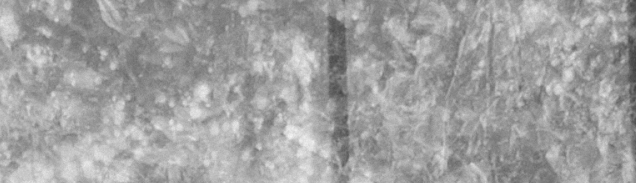

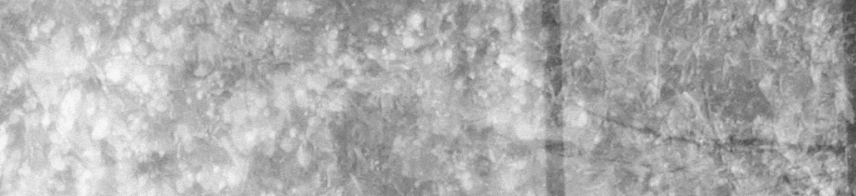

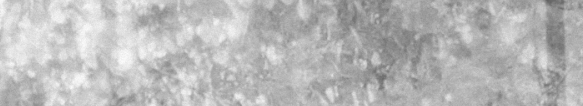
26. E.

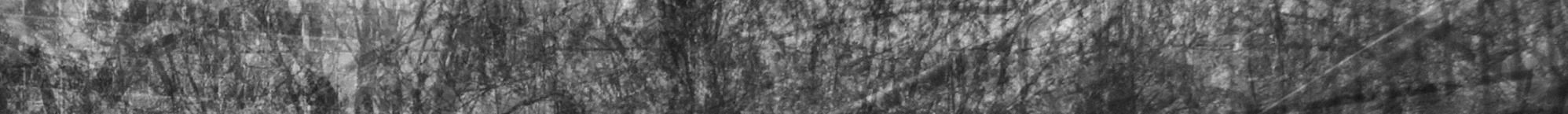
S. (2)

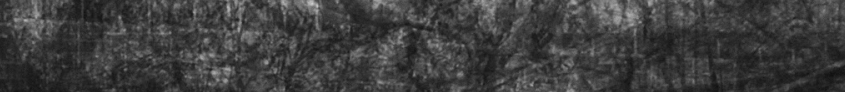
1.7.

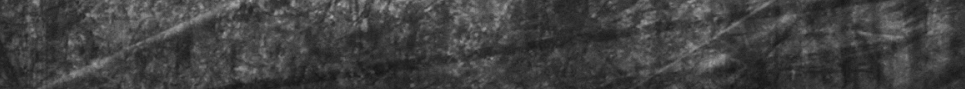
(1)

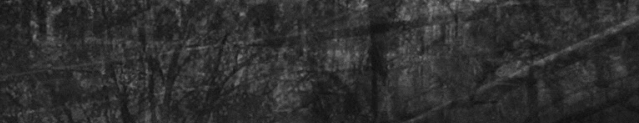
A. 190

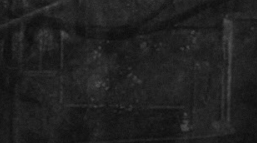

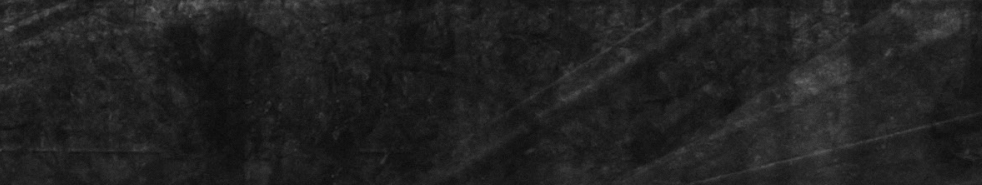

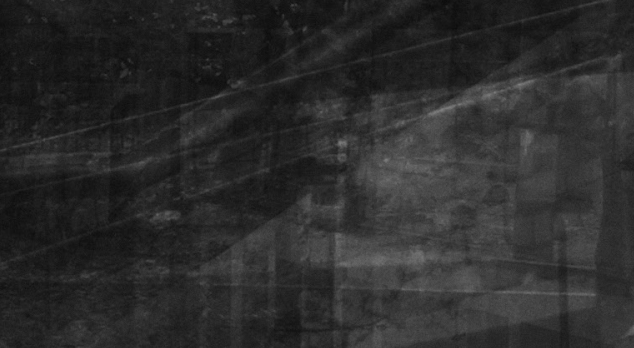




\section{References}

Aureli, P. V. (2010). The Possibility of an Absolute Architecture. Cambridge, MA: The MIT Press De Solá-Morales, I. (1995). Terrain vague. In Cynthia Davidson (Ed). Anyplace. Cambridge, MA: The MIT Press.

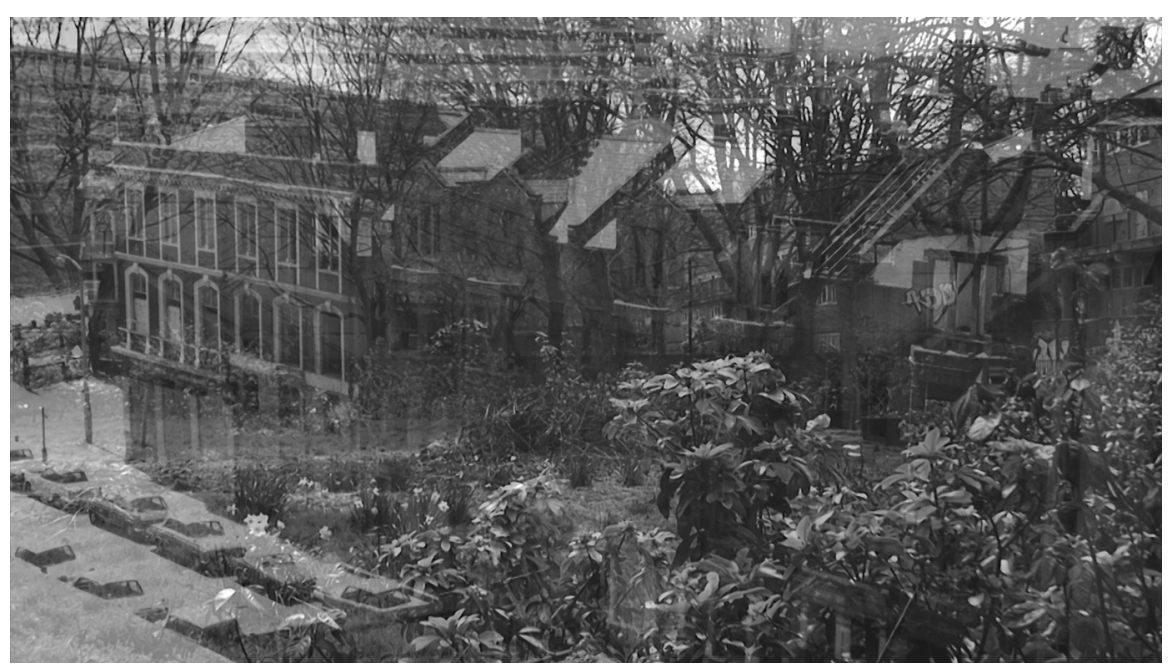

Fig. 11 (above) Superimposition of two photographs. The 1972 photograph looks towards buildings in Gurney Street (subsequently demolished) from a building in Pollock Street. It shows the old buildings prior to their demolition in the foreground, and one of the high rises of the Heygate Estate already under construction in the background. The second photograph corresponds to the current view and is taken from the same position and perspective as the 1972 photograph. [Photo: Author, 2013]

Fig. 12 (previous spread) Superimposition of seven photographs. The background photograph was taken prior to the construction of the Heygate Estate (ca. 1967) in what was then Pollock Street. Superimposed are six photographs taken on the 14th of May 2012 in the same area prior to the demolition of the Heygate Estate. [Photo: Author, 2012] 